\title{
Transmigration of impacted mandibular canines - case report
}

\author{
Transmigraţia caninilor mandibulari incluşi - prezentare de caz clinic
}

\author{
Mioara Decusară, Cerasella Dorina Şincar, Gabriela Popa, Gabriel Valeriu Popa \\ Departamentul de Medicină Dentară, Facultatea de Medicină şi Farmacie, \\ Universitatea „Dunărea de Jos“, Galaţi, România
}

\begin{abstract}
Transmigration is a rare dental anomaly, characterized by the presence of the mandibular canine impacted who cross-es the midline without signs or subjective manifestations. The formation of the impacted cuspid tooth takes place is in normal parameters, but at a given time, without a specific causal factor, the direction of the impacted canine is deviated towards the median and mandibular symphysis line, horizontally. Orthodontic treatment of mandibular canine transmi-gration is determined by radiographic examination, which specifies the intraosseous position of the tooth, the direction of migration, and the quality of the mandibular bone. In this article is presented the case of a 10year-old girl with mixed dentition, 33 impacted, but palpable bucally, located at the apex of the mandibular incisors, with sagittally-elongated symphysis chin, anterior reverse occlusion and inclination of the vestibule of the lower incisors. On the orthopantomo-gram, the horizontally impacted mandibular canine was identified, the crown exceeding the median line at the apex of the mandibular incisors. Surgical orthodontic treatment aimed at the alignment of the arches and the alignment of the included mandibular canine, obtaining the correspondence of the median and inter-incisal lines and correcting the frontal inverse occlusion.
\end{abstract}

Keywords: mandibular canine transmigration, orthodontic and surgical treatment

\begin{abstract}
REZUMAT
Transmigraţia este o anomalie dentară rară, caracterizată prin prezenţa caninului mandibular inclus care traversează linia mediană fără semne sau manifestări subiective. Formarea dintelui are loc în parametri normali, dar, la un moment dat, fără un factor cauzal specific, direcţia erupţiei canine incluse este deviată spre linia de simfiză mediană şi mandibulară, pe orizontală. Tratamentul ortodontic al transmigrării caninului mandibular este determinat prin examen radiografic, care specifică poziţia intraoză a dintelui, direcţia de migrare şi calitatea osului mandibular. În acest articol este prezentat cazul unei fetiţe de 10 ani, cu dentiţie mixtă, 33 inclus, dar palpabil în vestibulul bucal, situat în dreptul apexurilor incisivilor mandibulari, cu simfiza mentonieră alungită sagital, ocluzie inversă anterioară şi proclinarea incisivilor inferiori. Pe ortopantomogramă a fost identificat caninul mandibular inclus orizontal, coroana depăşind linia mediană în dreptul apexurilor incisivilor mandibulari. Tratamentul ortodontic-chirurgical a urmărit alinierea dinţilor bimaxilar şi a caninului mandibular transmigrat, obţinerea corespondenţei liniilor mediane şi interincisive şi corectarea ocluziei inverse frontale.
\end{abstract}

Cuvinte cheie: transmigraţia caninului mandibular, tratament ortodontic şi chirurgical

\section{INTRODUCERE}

Migrarea dinţilor este o ectopie dentară la care mecanismul determinant nu este clar cunoscut (1). Dintele afectat migrează într-o locaţie la o distanţă de locul de dezvoltare, dar rămâne, de obicei, în aceeaşi parte a arcului dentar (2). Atunci când mişcarea dintelui se face de-a lungul liniei mediane a maxilarului, fără influenţa vreunei entităţi patologice, se numeşte transmigrare (3). Aparent, migrarea intraosoasă a unui dinte începe în timpul dentiţiei mixte mixte şi poate avea loc pe o perioadă de mulţi ani (4). Dintele cel mai afectat de transmigraţie este caninul, cel mai frecvent fiind la mandibulă, probabil din cauza distanţei mai mari dintre apexurile dinţilor şi limita inferioară a mandibulei, ceea ce ar permite migrarea caninului spre zona simfizară, zonă care ulterior va creşte pentru a se adapta caninului migrator. 
Transmigrarea caninilor maxilari este foarte rară, ceea ce se poate datora distanţei mai scurte între rădăcinile incisivilor maxilari şi podeaua fosei nazale şi restricţionarea căii mişcării dinţilor de către rădăcinile dinţilor adiacenţi (5).

Etiologia acestei anomalii dentare rare nu este încă cunoscută şi există mulţi factori care contribuie la apariţia ei. Ereditatea a fost sugerată ca factor cauzativ. Cel mai frecvent acceptată explicaţie este deplasarea anormală a laminei dentare în viaţa embrionară şi neaderarea caninului care va transmigra. De asemenea, s-a subliniat că şi un obstacol foarte mic, cum ar fi un fragment de rădăcină mică sau un odontom, ar fi suficient pentru a devia un dinte de la calea sa normală de erupţie (6). Alţi autori au sugerat că agenezia incisivilor laterali permanenţi poate duce la o cale de erupţie deviată şi, prin urmare, la transmigrare (7).

Progresia unui canin mandibular inclus către linia mediană sau tendinţa de a traversa sutura simfizei mentoniere trebuie considerată un semn interceptiv de transmigrare şi astfel să poată lua decizia terapeutică pentru a corecta anormalitatea (13).

Prezenţa transmigraţiei ar trebui suspectată în cazurile în care caninul permanent inferior este absent din punct de vedere clinic, cu persistenţa caninului de lapte. Uneori, este asociată cu o dezvoltare anterioară a zonei simfizare mandibulare, fără simptomatologie dureroasă. Diagnosticul de certitudine este dat de examenul radiografic, respectiv ortopantomograma, care evidenţiază gradul de în-

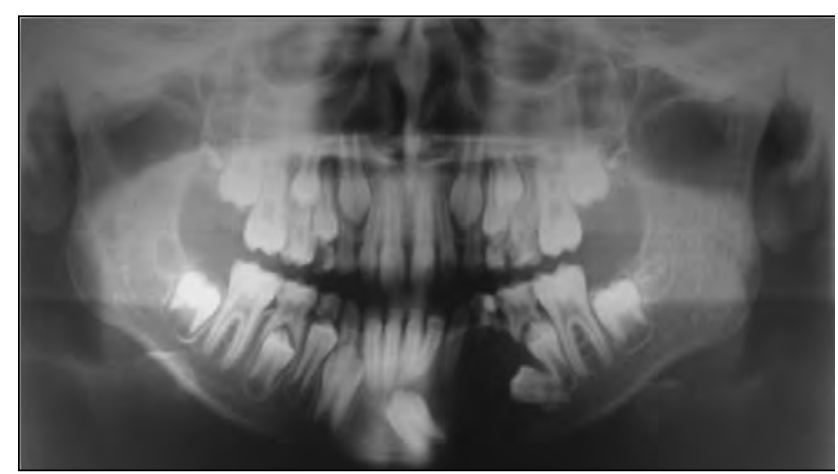

FIGURA 1-A. Ortopantomograma unui pacient de 9 ani evidențiază prezența unui chist (traumatic sau folicular) în hemimandibula stângă, care nu a produs rizaliză patologică a dinților supraiacenți, dar a modificat poziția mugurilor dentari 33 (care a migrat spre hemimandibula dreaptă şi a cărui coroană se află situată sub apexurile lui $41,31,32$ ) şi a lui 34 (care s-a orizontalizat); de remarcat subțierea corticalei marginii bazilare mandibulare subiacente chistului, explicându-se necesitatea unei intervenții chirurgicale de urgență (chistectomie), pentru reducerea riscului de apariție a unei fracturi mandibulare clinare a dintelui transmigrat, prezenţa unui obstacol în calea de erupţie, eventuale patologii intraosoase coexistente (rizaliza patologică a dinţilor adiacenţi, chist folicular etc.) (8) (fig. $1 \mathrm{a}, \mathrm{b}$ ).

Modalităţile de tratament pentru dintele transmigrat depind de stadiul de dezvoltare, distanţa de migrare şi de poziţia şi angulaţia dintelui atunci când este diagnosticat. Astfel, prin îndepărtarea chirurgicală a fragmentelor de rădăcină, a odontomului sau a unui chist care interferează cu calea normală de erupţie a unui dinte, se facilitează erupţia acestuia şi se îmbunătăţeşte poziţia faţă de dinţii învecinaţi (9). Dacă se observă pe ortopantomograma efectiuată în dentiţia mixtă că poziţia caninului mandibular se înclină progresiv mai mult către mezial, trebuie luate măsuri de intercepţie. Tratamentul preventiv şi interceptiv include extracţia caninului de lapte ce persistă pe arcadă şi expunerea chirurgicală a caninului afectat, urmată de tratament ortodontic. Acest lucru subliniază importanţa diagnosticului precoce pentru a remedia această problemă înainte ca dintele să migreze prea departe de locaţia sa iniţială.

Transplantarea este o altă abordare pentru salvarea dintelui transmigrat. Dacă caninul transmigrat este în poziţie favorabilă pentru îndepărtarea chirurgicală şi există un spaţiu suficient păstrat de caninul de lapte, se poate face transplantarea. Procedura se realizează cel mai bine atunci când lungimea rădăcinii dintelui este cuprinsă între o jumătate şi trei sferturi pentru restabilirea alimentării cu sânge (10).

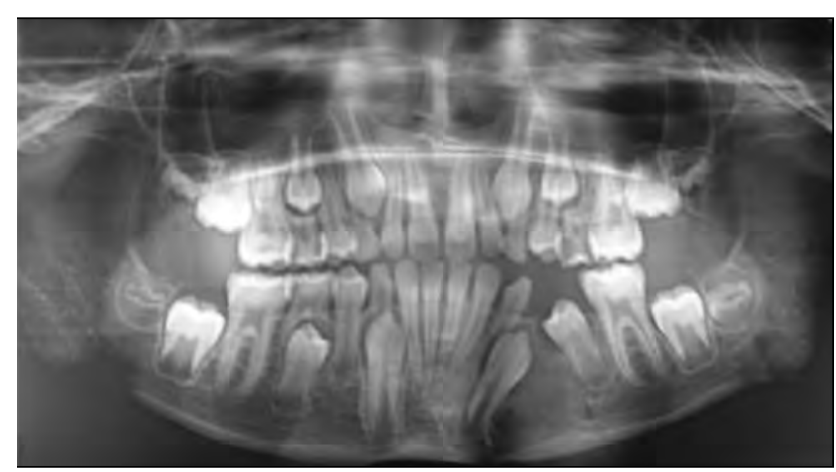

FIGURA 1-B. Ortopantomograma aceluiaşi pacient, la 6 luni după intervenția chirurgicală prin care s-a îndepărcat chistul folicular şi mugurele dentar al lui 34 (a cărui coroană se afla intrachistic). Se remarcă vindecarea osoasă, cu redresarea intraosoasă spontană a lui 33 (după îndepărtarea chistului) şi erupția uşor mezio-înclinată a lui 35, aceeaşi poziție mezializată a mugurelui dentar al lui 25, a cărui coroană apare peste jumătatea apicală a lui 24, fără a-i produce rizaliză patologică (posibil situat în palato-poziție), precum şi începutul mineralizării coronare ale celor patru molari de minte 
Îndepărtarea chirurgicală a caninului mandibular transmigrat este indicată atunci când coroana caninului a migrat spre partea opusă, imposibil de redresat ortodontic în poziţia ideală, mai ales în cazurile în care este asociată şi o patologie sau simptome neurologice (11).

În anumite situaţii, caninul transmigrat poate fi păstrat, dacă nu este prezentă vreo simptomatologie şi dacă nu este asociat cu vreo patologie. La aceşti pacienţi, trebuie făcute radiografii periodice pentru a verifica starea dintelui transmigrat. În caz de agravare continuă a poziţiei sau de dezvoltare a leziunii chistice şi în cazul resorbţiei radiculare severe a dinţilor adiacenţi, este indicată îndepărtarea chirurgicală (12).

\section{PREZENTARE DE CAZ CLINIC}

O fetiţă de 10 ani s-a prezentat împreună cu mama ei pentru un consult ortodontic, la recomandarea medicului stomatolog generalist, care a observat radiologic prezenţa lui 33 inclus orizontal.

La examenul facial, pacienta prezenta:

- facies oval, asimetric, punctul Gnation fiind deviat spre stânga

- etajul inferior redus cu un profil concav, determinat de Gnation anterior de planul orbital-frontal al lui Simon

- treapta labială inversată

- şanţ labiomentonier şters

- unghiul goniac în limite normale.

Examinarea endobucală a evidenţiat (fig. 2):

- dentiţie mixtă cu prezenţa molarilor temporari secunzi, bilateral şi bimaxilar, şi persistenţa rădăcinii 73 fără mobilitate fiziologică, cu spaţiul redus pentru erupţia şi alinierea lui 33

- malpoziţii dentare, cu 13 şi 23 în infra-mezio-vestibulopoziţie, cu spaţiu redus pentru aliniere
- relaţii ocluzale de clasa III la nivel molar şi canin, bilateral

- ocluzie inversă frontală, cu supraacoperire inversă de $1 / 2$ şi vestibulo-înclinarea grupului frontal mandibular

- liniile mediane şi incisive deviate cu $5 \mathrm{~mm}$ spre stânga

- palparea în vestibulul bucal a coroanei lui 33 inclus, în dreptul apexurilor lui 32, 31, 41.

La examenul funcţional s-a constatat:

- blocarea mişcărilor funcţionale de propulsie şi lateralitate, cu devierea mandibulei spre stânga, la închiderea gurii

- mişcarea de retropulsie mandibulară pozitivă, până la la poziţia cap-la-cap (labiodontia) a incisivilor

Examinarea ortopantomogramei (fig. 3) a confirmat prezenţa lui 33 inclus orizontal, coroana depăşind linia mediană, în dreptul apexurilor lui 41, 31 şi 32, fără a produce rizaliză patologică, luând în considera transmigrarea lui 33. De asemenea, s-a observat prezenţa premolarilor secunzi, cu rădăcini în formarea şi a mugurilor molarilor de minte, cu debut de mineralizare coronară.

Planul de tratament propus şi acceptat de pacient şi familie a fost:

- aplicarea unui aparal ortodontic fix bimaxilar pentru alinierea arcadelor dentare şi pentru a obţine spaţiu pentru 13, 23 şi 33.

- descoperirea chirurgicală a coroanei 33 şi aplicarea unui ataş ortodontic cu lănţişor pentru ancorarea şi tracţiunea caninului mandibular transmigrat la locul de erupţie şi alinierea acestuia

- înălţare temporară ocluzală la nivelul molarilor primi pentru corectarea ocluziei inverse frontale

- extracţia în scop ortodontic a lui 45 , cu deplasarea distală a lui 44 şi 43 şi a grupului incisiv
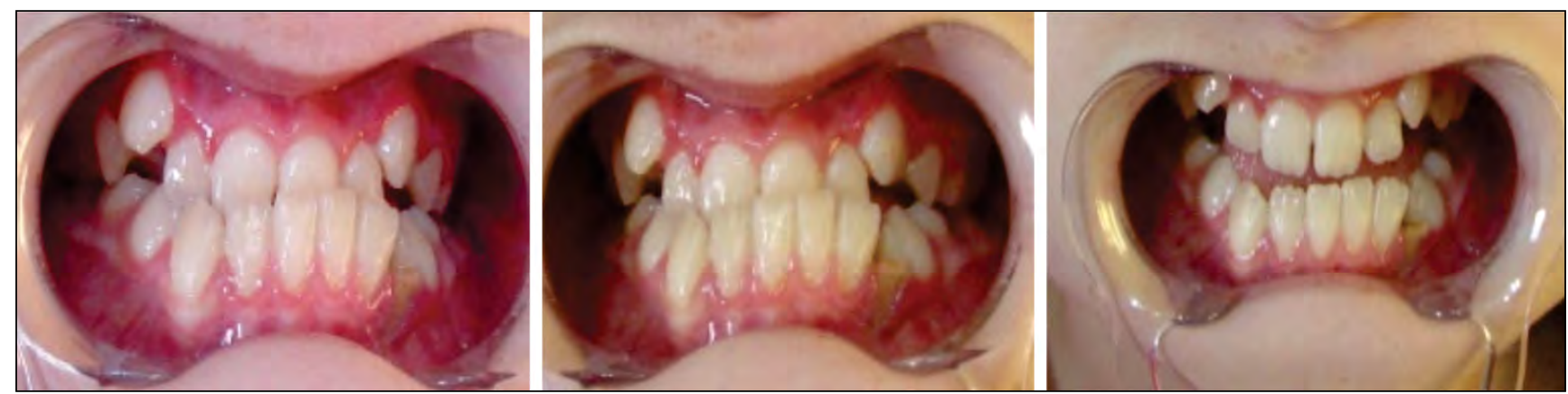

FIGURA 2. Imaginea arcadelor dentare înaintea începerii tratamentului ortodontic 


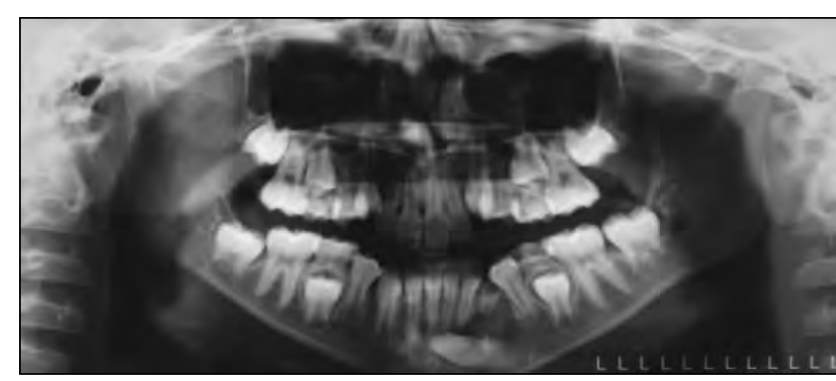

FIGURA 3. Ortopantomograma pacientei la începutul tratamentului ortodontic

mandibular, pentru obţinerea corespondenţei liniilor mediane şi interincisive.

La o lună după începerea tratamentului ortodontic, s-a efectuat descoperirea chirurgicală a coroanei caninului mandibular transmigrat (fig. 4), cu aplicarea unui ataş ortodontic cu lănţişor la nivelul coroanei lui 33, pentru redresarea ortodontică.

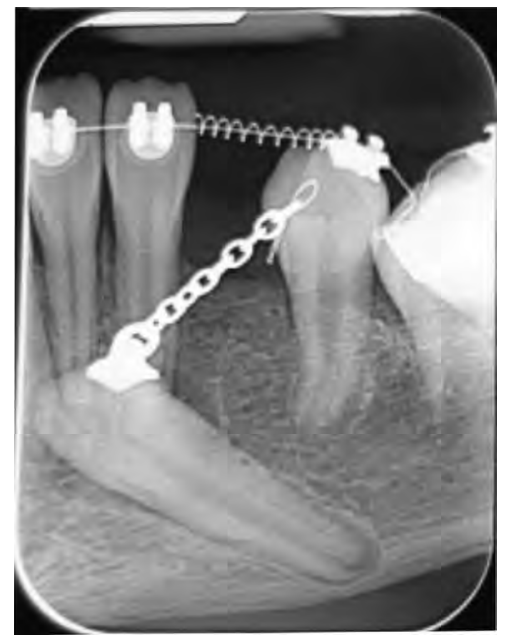

FIGURA 4. Descoperirea chirurgicală a coroanei caninului mandibular transmigrat

După 16 luni, a fost observată erupţia pe arcadă a lui 33, s-a înlocuit ataşul cu un bracket şi s-a ancorat la nivelul arcului ortodontic, pentru aliniere (fig. 5). După 24 de luni de la începerea tratamentului ortodontic a fost extras 45 , cu închiderea ulterioară a spaţiului prin deplasarea distală a lui 44 şi 43 şi a grupului incisiv inferior.

La 40 de luni de la începerea tratamentului ortodontic, a fost îndepărtat aparatul dentar fix, au fost stabilite relaţii neutrale la nivel molar şi canin (cu excepţia molarilor de partea dreapta, unde s-a obţinut un raport mezializat terapeutic), corespondenţa liniilor mediane, cu acoperirea de $1 \mathrm{~mm}$ la nivelul incisivilor centrali şi o inocluzie verticală de $1 \mathrm{~mm}$ între 22, 23, 24 şi antagonişti, determinată de obiceiul de deglutiţie infantilă laterală (probabil instalat în perioada înălţării temporare a ocluziei pentru a corecta ocluzia frontală) (fig. 6).

Ortopantomograma efectuată la finalul tratamentului ortodontic a evidenţiat statusul coronoradicular al caninului mandibular transmigrat, alinierea dentară bimaxilară şi spaţiul redus pentru erupţia molarilor de minte (coroana fiind mineralizată). S-a recomandat control periodic la 6-12 luni, cu dispensarizarea erupţiei molarilor de minte şi indicaţia de extracţie a acestora (mai ales a celor mandibulari, care pot determina un puseu de creştere mandibulară, având în vedere tiparul hiperdivergent evidenţiat pe teleradiografia de profil) (fig. 7).

\section{CONCLUZII}

Caninii mandibulari pot fi consideraţi ca o „piatră de temelie" la nivelul arcadelor dentare, având un rol important în eficienţa funcţiei masticatorii, la stabilitatea arcului dentar şi la menţinerea esteticii şi expresiei faciale. Detectarea precoce a transmigraţiei de canin poate ajuta la conservarea acestor canini prin intervenţie chirurgical-ortodontică.

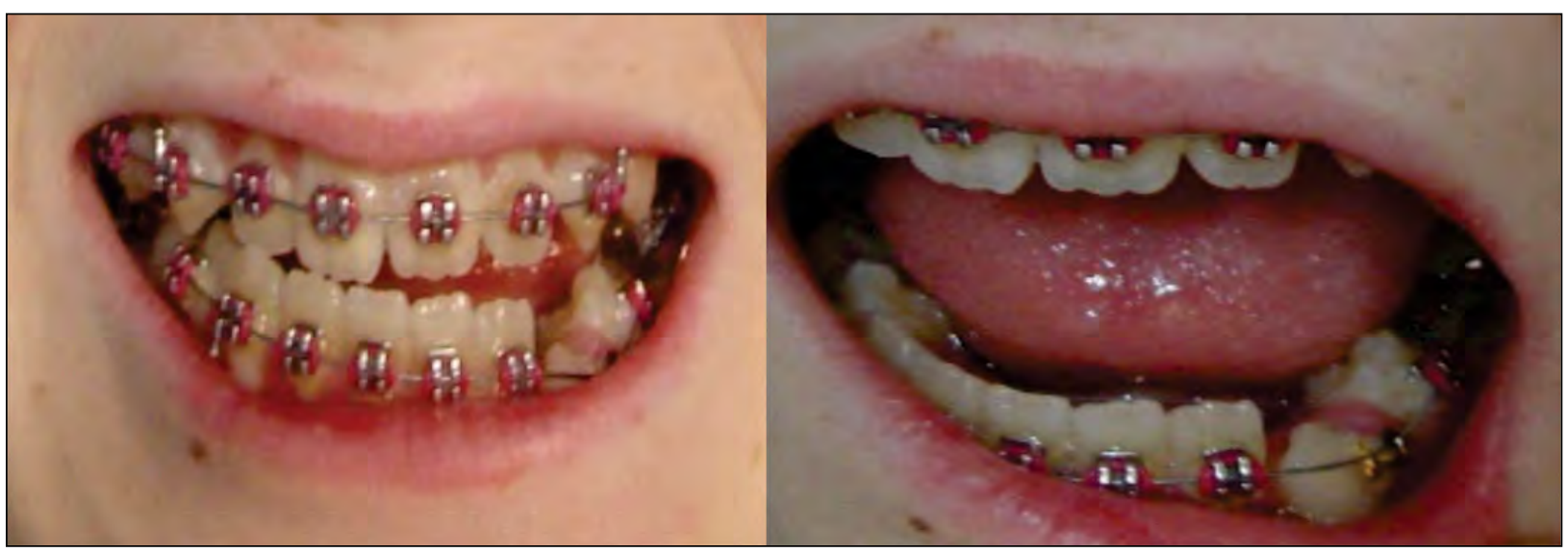

FIGURA 5. Imaginea arcadelor dentare la 16 luni de la începerea tratmentului ortodontic 

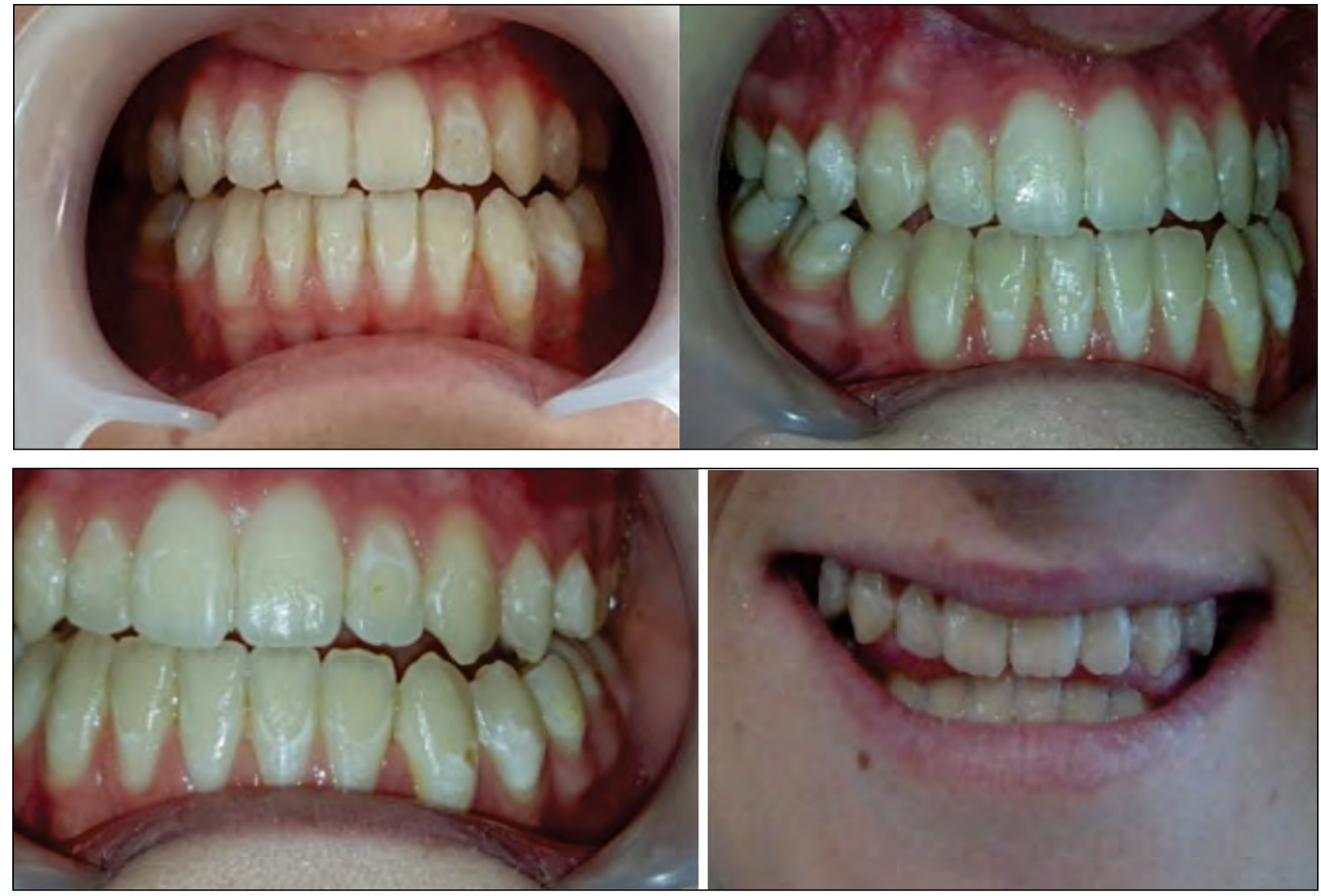

FIGURA 6. Imaginea arcadelor dentare şi a ocluziei la finalul tratamentului ortodontic (se observă obiceiul deglutiției infantile laterale)
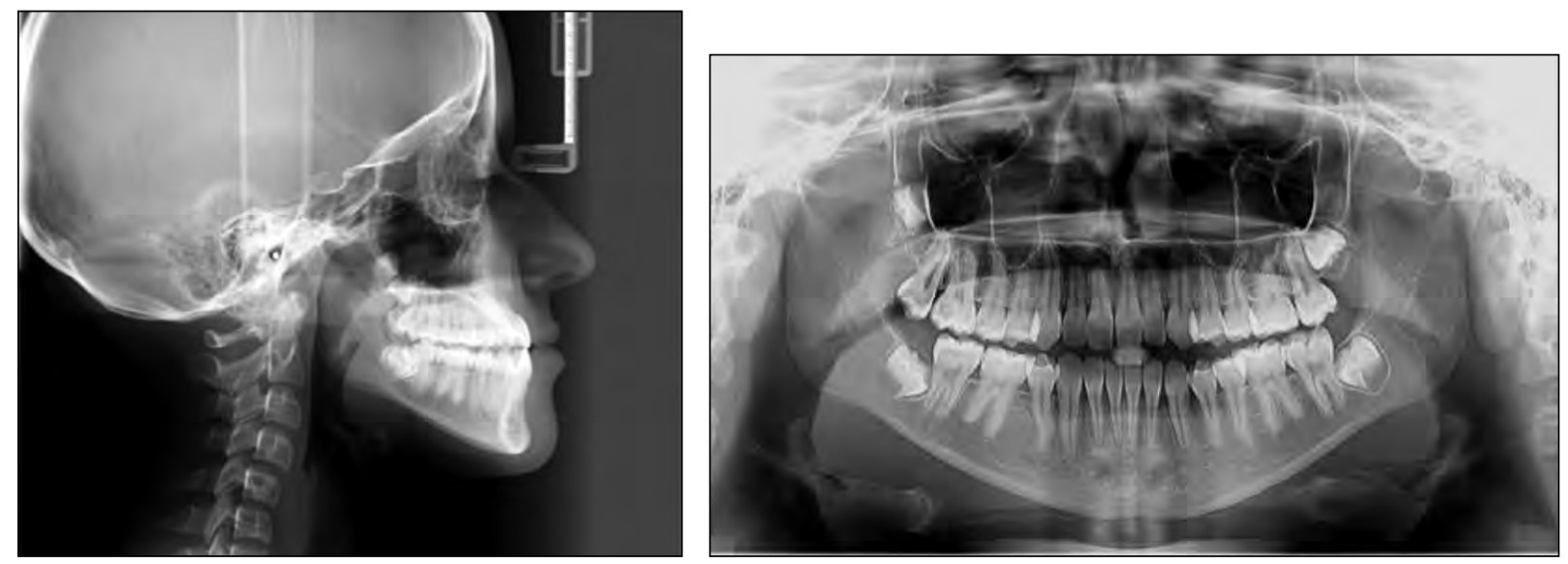

FIGURA 7. Aspectul radiografic al arcadelor la finalul tratamentului ortodontic

Această anomalie de dezvoltare şi erupţie este diagnosticată în mod corespunzător prin evaluare radiografică, pe baza ortopantomogramei, mai ales dacă este efectuată la pacienţi cu dentiţie mixtă.

Tratamentul preventiv şi interceptiv include extracţia caninului de lapte ce persistă pe arcadă şi expunerea chirurgicală a caninului afectat, urmată de tratament ortodontic. Acest lucru subliniază importanţa diagnosticului precoce pentru a remedia această problemă înainte ca dintele să migreze prea departe de locaţia sa iniţială.

\section{BIBLIOGRAFIE}

1. Shapira $Y$, Borell $G$, Kuftinec MM, Nahlieli O. Bringing impacted mandibular second premolars into occlusion. Journal of the American Dental Association. 1996; 127(7):1075-1078.
2. Camilleri S, Scerri E. Transmigration of mandibular canines-a review of the literature and a report of five cases. Angle Orthodontist. 2003; 73(6):753-762. 
3. Joshi MR. Transmigrant mandibular canines: A record of 28 cases and a retrospective review of the literature. The Angle Orthodontist. 2001;71:12-22.

4. Peck S. On the phenomenon of intraosseous migration of nonerupting teeth. American Journal of Orthodontics and Dentofacial Orthopedics. 1998;113(5):515-517.

5. Ryan FS, Batra P, Witherow H, Calvert M. Transmigration of a maxillary canine. A case report. Primary Dental Care. 2005; 12(2):70-72.

6. Nodine AM. Aberrant teeth, their history, causes, and treatment. Dental Items of Interest. 1943; 65:440-451.

7. Ando S, Aizaea K, Nakashima T, Sanka Y, Shimbo K, Kiyokawa K. Transmigration process of impacted mandibular cuspid. The Journal of Nihon University School of Dentistry. 1964;6:66-71.

8. Mioara Decusară. Utilizarea ortopantomogramei în practica stomatologică. Zigotto Publishing House, Galați, 2017, ISBN: 978-606-669-263-2.
9. Wertz RA. Treatment of transmigrated mandibular canines. American Journal of Orthodontics and Dentofacial Orthopedics. 1994; 106(4):419-427.

10. Northway WM, Konigsberg S. Autogenic tooth transplantation. The 'state of the art' American Journal of Orthodontics. 1980; 77(2):146-162.

11. Verma SL, Sharma VP, Singh GP. Management of a transmigrated mandibular canine. Journal of Orthopaedic Science. 2012; 11(1):23-28.

12. Trakyali G, Cildir SK, Sandalli N. Orthodontic treatment of a transmigrated mandibular canine: A case report. Australian Orthodontic Journal. 2010; 26(2):195-200.

13. Mioara Decusară, Gabriel Valeriu Popa, Cerasella Dorina Şincar. The relevance of orthopantomograms use in orthodontic practice. $J$ Med Res Prac, 2017, 6(6): 189-194. 